Como citar: Kaus, D., Barbosa, T. P., \& Paludo, S. dos S. (2021). Fluxo de atendimento à mulheres em situação de violência: caminhos e perdas. PSI UNISC, 5(2), 78-94. doi: 10.17058/psiunisc.v5i2.16514

\title{
Fluxo de atendimento à mulheres em situação de violência: caminhos e perdas
}

\author{
Flujo de atención a las mujeres en situaciones de violência: caminos y pérdidas
}

Flow of care for women in situations of violence: paths and losses

Universidade Federal do Rio Grande (FURG), Rio Grande - RS/Brasil

ORCID: 0000-0002-3014-2523

E-mail: dieniferkaus@gmail.com

Thamires Pereira Barbosa

Universidade Federal de Santa Maria (UFSM), Santa Maria - RS/Brasil

ORCID: 0000-0002-7292-9148

E-mail: thami.pereira@gmail.com

Simone dos Santos Paludo

Universidade Federal do Rio Grande (FURG), Rio Grande - RS/Brasil

ORCID: 0000-0002-3281-5824

E-mail: simonepaludo@yahoo.com.br

\begin{abstract}
Resumo
A violência contra a mulher é uma das principais formas de violação dos direitos humanos e uma das problemáticas mais graves enfrentadas pela mulher na atualidade. Para romper com o ciclo da violência, muitas mulheres buscam ajuda com profissionais da rede de suporte social. Frente à sua complexidade e dada à importância do atendimento multiprofissional e qualificado a estas mulheres, este artigo tem como objetivo identificar o fluxo de atendimentos e os encaminhamentos desse grupo na rede de proteção em um município do interior do Rio Grande do Sul - RS. Foram coletados os dados, através de um estudo documental, de 66 casos de mulheres em situação de violência que chegaram até o CREAS no ano de 2019. Foram identificados 38 atendimentos e 28 casos encaminhados que nunca chegaram ao CREAS. Verificou-se que os caminhos que as mulheres percorrem são múltiplos e cheios rupturas. O fluxo de atendimentos na rede de proteção à violência contra mulher ainda se mostra frágil, o que prejudica a mulher no enfrentamento efetivo à violência.
\end{abstract}

Palavras-chaves: Mulheres; Rede de Proteção; CREAS; Violência; Psicologia.

\section{Resumen}

La violencia contra la mujer es una de las principales formas de violación de los derechos humanos y uno de los problemas más graves que enfrentan las mujeres en la actualidad. Para romper el ciclo de la violencia, muchas mujeres buscan ayuda de profesionales en la red de apoyo social. Dada su complejidad y dada la importancia de la atención multidisciplinaria y calificada para estas mujeres, el estudio tiene como objetivo identificar el flujo de atención y las derivaciones de este grupo en la red de protección en una ciudad del interior de Rio Grande do Sul - RS. Se recolectaron datos, a través de un estudio documental, de 66 casos de mujeres en situación de violencia que llegaron al CREAS en 2019. Se identificaron 38 casos en CREAS y 28 casos que nunca llegaron al CREAS. Se encontró que los caminos que toman las mujeres son múltiples y llenos de rupturas. El flujo de asistencia en la red para la protección contra la violencia contra la mujer es aún frágil, lo que perjudica a las mujeres para enfrentar la violencia de manera efectiva.

Palabras clave: Mujeres; Red de protección; CREAS; Violencia; Psicología.

\footnotetext{
Abstract

Violence against women is one of the main forms of human rights violations and one of the most serious problems faced by women today. To break the cycle of violence, many women seek help from professionals in the social support network. In view of its complexity and given the importance of multidisciplinary and qualified care for these women, the study aims to identify the flow of care and the referrals of this group in the protection network in a city in the interior of Rio Grande do Sul RS. Data were collected, through a documentary study, of 66 cases of women in situations of violence who arrived at CREAS in 2019. 38 cases were identified at
} 
CREAS and 28 cases referred never reached CREAS. It was found that the paths that women take are multiple and full of ruptures. The flow of assistance in the network for the protection against violence against women is still fragile, which harms women in effectively confronting violence.

Keywords: Women; Protection net; CREAS; Violence; Psychology.

\section{Introdução}

A violência contra a mulher é uma das principais formas de violação dos direitos humanos e uma das problemáticas mais graves enfrentada pelas mulheres na atualidade (Brasil, 2011a). Compreende qualquer ato violento que inclua ameaças, coerções, privação da liberdade baseada no gênero e que resulte ou possa resultar em danos nas esferas física, sexual e/ou emocional (United Nations [ONU], 1993). É estimado que cause mais mortes às mulheres de 15 a 44 anos do que o câncer, a malária, os acidentes de trânsito e as guerras (Gomes, Minayo, \& Silva, 2005). Devido à sua magnitude, vem sendo considerada uma problemática de saúde pública (World Health Organization [WHO], 2013).

Este tipo de violação é uma modalidade específica da violência que ocorre nas relações afetivas e envolve as dimensões de poder reforçando a inequidade de gênero (Romagnoli, Abreu, \& Silveira, 2013). No Brasil, em média, uma em cada cinco brasileiras já sofreu algum tipo de violência doméstica ou familiar e, em sua maioria, o agressor é o marido ou ex parceiro (Brasil, 2015; Romagnoli et al., 2013). Além disso, dados apontam que um em cada cinco dias de ausência no trabalho é devido à violência doméstica sofrida pelas mulheres, a qual faz com que a cada cinco anos de violência sofrida, a mulher perca um ano de vida saudável (Ribeiro \& Coutinho, 2011).

Este fenômeno, não discrimina nível de escolaridade, camada social ou idade (Cunha, 2008; Mascarini \& Miranda, 2018), mas tem relação direta com gênero. Isso significa que o conjunto de construções sociais e históricas sobre as categorias de homem e mulher, as quais envolvem estratégias de poder, dominação e submissão, são centrais nessa modalidade (Romagnoli et al., 2013). A violência doméstica e familiar contra a mulher é caracterizada como toda a ação ou omissão baseada no gênero feminino, que provoque morte, lesão, sofrimento físico, sexual ou psicológico e dano moral ou patrimonial a partir das relações estabelecidas no âmbito da unidade doméstica, da família e das relações íntimas de afeto. As formas de manifestação desta violência são tipificadas em: violência física, violência psicológica, violência sexual, violência patrimonial e violência moral (Lei n. 11.340, 2006).

Dentre os tipos de violência sofrida entre as mulheres, as que apresentam maior frequência são as violências psicológica e física (Instituto Brasileiro de Geografia e Estatística [IBGE], 2014; Brasil, 2015), seguida pela sexual (Barros \& Schraiber, 2017). Já a patrimonial e a moral não têm grande visibilidade e são pouco conhecidas entre a população (IBGE, 2014; Brasil, 2015). A física tem maior visibilidade entre as mulheres, sendo que na pesquisa de Zacan, Wassermann e Lima (2013), é reconhecida como a mais perigosa. Entretanto, o estudo de Sagot (2007), citado por Zacan et al. (2013), aponta que, segundo os relatos das mulheres, a agressão psicológica é a mais dolorosa.

Os índices mundiais mostram que $30 \%$ das mulheres admitem já ter sofrido violência física ou sexual por seu parceiro, ao longo da vida, e $38 \%$ dos assassinatos contra mulheres são cometidos por seu parceiro ou ex-parceiro íntimo (WHO, 2014). A violência contra a mulher por parceiro íntimo (VPI) é uma das mais prevalentes e endêmicas formas de violência neste âmbito (Silva \& Oliveira, 2015). Pode trazer consequências como: isolamento social, incapacidade para exercer atividades laborais e, por conseguinte, perda de salário, prejuízo na realização de atividades cotidianas, além da limitação no cuidado 
consigo e com os outros (Mendonça \& Ludermir, 2017).

A violência no âmbito conjugal se manifesta de forma cíclica, vai se modificando em forma de espiral e se intensificando ao longo do tempo (Mascarini \& Miranda, 2018). As mulheres que vivenciam essas situações de violência tendem a apresentar baixa autoestima, o que pode torná-las mais vulneráveis e propensas a vitimização, pois não percebem a gravidade da situação (Adeodato, Carvalho, Siqueira, \& Souza, 2005; Barros et al., 2016). E, devido a fatores sociais, econômicos e afetivos, essas mulheres podem encontrar dificuldades para romper com o ciclo de violações (Adeodato et al., 2005; Barros et al., 2016; Vieira, Perdona, \& Santos, 2011).

A dependência econômica do parceiro, a falta de apoio familiar, a presença de filhos com o agressor, a esperança de mudança de comportamento do companheiro e o medo das ameaças sofridas são fatores que podem levar a mulher a permanecer em um relacionamento violento (Barros et al., 2016; Carneiro \& Fraga, 2012; Lei n. 11.340, 2006; Zacan, Wassermann, \& Lima, 2013). A mulher em situação de violência pode desenvolver uma crença de que é merecedora da violência sofrida, devido a sentimentos de culpa e visão negativa de si. Ela pode acreditar que será abusada, humilhada e manipulada por quaisquer pessoas, o que contribui para a manutenção do ciclo violento (Barbosa, Corrêa, Zimmer, \& Paludo, 2019).

A dominação masculina e a desqualificação do feminino também são fatores que estão enraizados em muitas relações (Romagnoli et al., 2013), dessa forma a cultura patriarcal contribui para o desenvolvimento e manutenção do fenômeno da violência (Narvaz \& Koller, 2006). A violência contra a mulher é um fenômeno multifatorial e a sua ruptura envolve diversos fatores que ultrapassam o comportamento da mulher. É possível ainda que as barreiras para a busca por ajuda estejam pautadas nas hierarquias rígidas, nos estereótipos de gênero e nas dificuldades impostas pelos serviços que fazem parte da rede de proteção. A literatura tem tentado compreender esse caminho e tem identificado que, para romper com o ciclo da violência, muitas mulheres buscam ajuda nos mais diversos serviços (delegacias e centros de referência em assistência social), embora sua procura aconteça, principalmente, quando há risco de morte (Labronici, 2012). Dentre as instituições procuradas por estas mulheres, estão a polícia/delegacia $(36,8 \%)$, as organizações de proteção à mulher/abrigos $(10,5 \%)$, os centros de saúde $(5,3 \%)$ e os ambulatórios de saúde mental (5,3\%) (Bruschi, Paula \& Bordin, 2006).

A busca por ajuda revela um caminho longo e, por vezes, repetido. Ao analisar dados dos boletins de ocorrência, Romagnoli et al (2013) identificaram que mais da metade das mulheres que procuraram a polícia e registraram queixa já tinha sofrido uma agressão anterior. A violência faz parte de seus cotidianos e, muitas vezes, perpassa várias gerações (Farinha \& Souza, 2016). Por esse motivo, o enfrentamento da violência precisa ser amplo e envolver prevenção, atendimento e repressão.

A década de 1980, no Brasil, marca um dos primeiros avanços no combate da violência com a criação das Delegacias da Mulher (Silveira, Nardi, \& Spindler, 2014). As Delegacias Especializadas de Atendimento à Mulher (DEAM) têm como objetivo proporcionar condições adequadas para que as mulheres que se encontram em situação de violência denunciem os crimes de forma segura e humanizada (Tavares, Rodrigues, Barroso, Vieira, \& Souza, 2017).

Outro importante reforço veio com a promulgação da Lei $\mathrm{n}^{\circ} 11.340$ (Lei Maria da Penha), em 2006. A Lei Maria da Penha tem como foco a prevenção, punição e erradicação do fenômeno no país (Lei n. 11.340, 2006; Mascarini \& Miranda, 2018). Também previu a criação dos Juizados de Violência Doméstica e Familiar contra a Mulher e implementou atendimentos especializados por equipes multidisciplinares (Curia et al., 2020). Esses dispositivos acentuaram as políticas de 
prevenção e de proteção às mulheres (Souza \& Cortez, 2014; Ávila, 2018). Foi nesse momento que se tornou possível a intervenção direta do Estado (esfera pública) na vida privada (Meneghel \& Vial, 2008; Souza, Santana, \& Martins, 2018).

Mais recentemente, em 2015, a alteração no Código Penal e a Lei 13.104/2015, prevê o feminicídio como circunstância qualificadora do crime de homicídio e passa a considerar esse tipo de crime como hediondo, por ser cometido por razões da condição de sexo feminino (Brasil, 2018; Mascarini \& Miranda, 2018). Com a lei, os assassinatos realizados por homens contra suas companheiras atuais ou passadas, incluindo também relacionamentos ocasionais passaram a ser considerados com maior gravidade (Mascarini \& Miranda, 2018).

Embora muitas mulheres ainda compreendam a violência como um problema de segurança pública e recorram as delegacias (Maffei, Marcos, \& Paludo, 2020), a assistência deve ser intersetorial e integral (WHO, 2013). $\mathrm{O}$ enfrentamento da violência deve acontecer em rede, isso significa que as instituições/equipamentos governamentais e não governamentais (assistenciais, saúde, segurança, justiça, dentre outros) precisam garantir as suas funções, estabelecer comunicação e atuar de forma horizontal sem hierarquia (d'Oliveira, Schraiber, Hanada \& Durand, 2009). Para isso, existe uma rede que está apoiada em diferentes setores/áreas (Brasil, 2011b) e uma atuação articulada pode proporcionar melhor qualidade no atendimento, identificação e encaminhamento adequado, além do desenvolvimento de estratégias efetivas de prevenção (Sani \& Morais, 2015). No entanto, pouco se conhece sobre os caminhos tomados pelas mulheres. A busca por apoio nas redes e nos serviços tem sido discutida como a rota crítica que as mulheres percorrem. Arboit, Padoin e Paula (2019) destacam que a rota nem sempre é linear e depende de uma série de fatores que incluem desde a percepção da mulher até as respostas da rede. Pesquisas têm sugerido uma infraestrutura e articulação da rede precárias
(Curia et al., 2020) que, ao se mostrar ineficiente, contribui para a perpetuação da violência (Souza et al., 2018).

Frente à complexidade da violência contra a mulher e dada à importância do atendimento integrado e intersetorial, o presente estudo tem como objetivo identificar o fluxo de atendimentos e os encaminhamentos desse grupo na rede de proteção em um município do interior do Rio Grande do Sul RS.

\section{Método}

Trata-se de um estudo de caráter documental retrospectivo com o objetivo de identificar o fluxo de atendimentos e os encaminhamentos de mulheres em situação de violência na rede de proteção em um município de médio porte no interior Rio Grande do Sul RS, no ano de 2019. A pesquisa documental baseia-se em dados que não receberam ainda um tratamento analítico, devido à subsistência dos documentos com o passar do tempo, é considerada uma fonte rica e estável para a coleta de material, além de não exigir o contato direto com pessoas (Gil, 2002; Carneiro \& Fraga, 2012). Para esse estudo foram acessados os dados registrados nos prontuários de atendimento do Centro de Referência Especializado de Assistência Social - CREAS. Foi priorizada a busca dos registros referentes às mulheres atendidas no serviço devido à situação de violência, no ano de 2019. Nos prontuários foram identificadas as seguintes variáveis: porta de entrada (serviços acessados pela mulher antes de chegar ao CREAS); idade; cor da pele; escolaridade; número de filhos; situação econômica; tempo de relacionamento; tipo de relacionamento; tipo de violência sofrida e encaminhamentos realizados.

Foi utilizado um protocolo padrão, elaborado pelas pesquisadoras, para coletar as variáveis de interesse. Foram incluídos no estudo todos os casos envolvendo mulheres em situação de violência que chegaram no dispositivo no período compreendido entre 01 de janeiro de 2019 a 31 de dezembro de 2019. A coleta de dados aconteceu nos meses de abril 
e maio de 2020. Para a realização da análise dos dados, foi criado um banco de dados no programa estatístico Statistical Package for the Social Sciences - SPSS. Os dados obtidos foram submetidos à análise estatística descritiva.

O estudo seguiu a resolução 510/2016 (Resolução n. 510, 2016). Um Termo de Autorização para acesso aos dados registrados nos prontuários de atendimento do Centro de Referência Especializado de Assistência Social - CREAS foi assinado pelo dirigente do serviço. Foi mantido o anonimato e confidencialidade das participantes e, para o CREAS, foi assumido o compromisso em utilizar os dados somente com cunho científico.

\section{Resultados e discussão Fluxo de atendimentos e articulação da rede}

A pesquisa foi realizada em um município de médio porte, situado no extremo sul do estado do Rio Grande do Sul. O município conta com serviços especializados para os casos de violência contra as mulheres, como: Juizado de Violência Doméstica e Familiar, Delegacia Especializada de Atendimento à Mulher (DEAM), Patrulha Maria da Penha, Casa de Acolhida da Mulher e Coordenadoria de Políticas Públicas para as Mulheres. Além disso, o município também conta com serviços não especializados que fazem parte da rede de atendimentos às mulheres em situação de violência, como: Delegacia Civil, Núcleo Ampliado de Saúde da Família e Atenção Básica (NASF), Centro de Referência da Assistência Social (CRAS), Conselho Tutelar, Centro de Referência Especializado de Assistência Social (CREAS), Centro de Atenção Psicossocial (CAPS), Defensoria Pública, Hospital Universitário (HU) e Promotoria da Secretaria Municipal de Cidadania e Assistência Social (SMCAS). De acordo com IBGE (2010), são ofertados 45 estabelecimentos de saúde SUS para aproximadamente 197 mil habitantes. Desta população, 32,9 \% tem um rendimento nominal mensal per capita de até $1 / 2$ salário mínimo e uma taxa de escolarização (de 6 a 14 anos de idade) de $97,7 \%$. As mulheres são cerca de 52\% (aproximadamente 102 mil) da população.

No ano de 2019 foram registrados e encaminhados para a Delegacia Especializada de Atendimento à Mulher local 1.933 boletins de ocorrência. A partir da análise dos documentos foi possível identificar que 66 casos de mulheres em situação de violência chegaram até o CREAS no ano de 2019. Levando em consideração que apenas 66 mulheres foram encaminhadas para o CREAS é possível afirmar que apenas $3,4 \%$ dos casos registrados no município receberam algum atendimento intersetorial. A Figura 1 apresenta o fluxo dos casos que alcançaram o CREAS: 


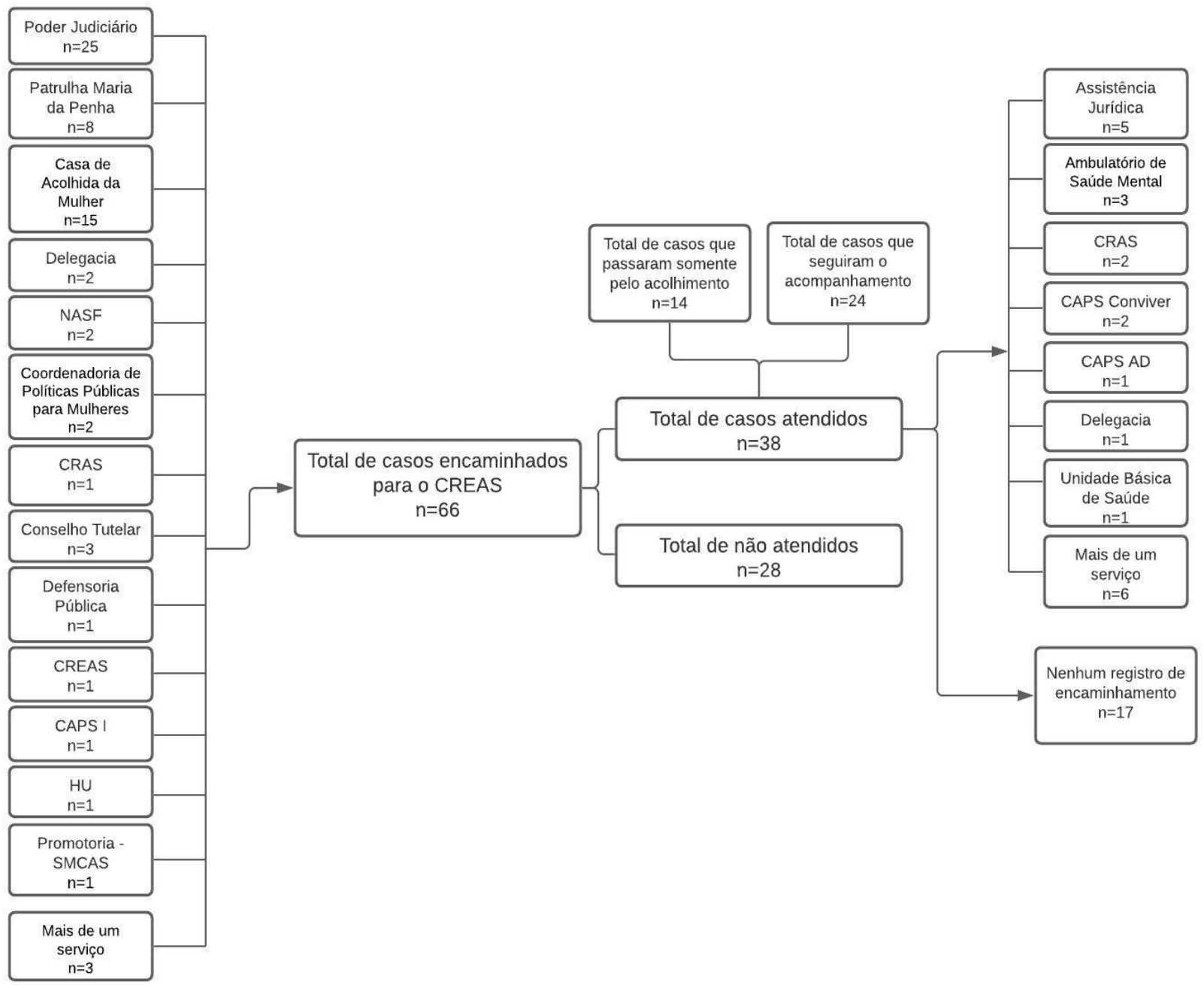

Figura 1. Fluxo dos casos de mulheres em situação de violência que alcançaram o CREAS em 2019

Ao analisar o caminho percorrido pelas mulheres em situação de violência que chegaram ao CREAS, é possível verificar que em 52 casos o primeiro acolhimento aconteceu em um serviço especializado de atendimento à mulher (Poder Judiciário - Vara de Violência Doméstica e Familiar, Patrulha Maria da Penha ${ }^{1}$, Casa de Acolhida da Mulher e Coordenadoria de Políticas Públicas para Mulheres). Isso significa que $78,78 \%$ dessa amostra acessou serviços que possuem expertise no tema da violência contra a mulher, revelando que possivelmente as mulheres

\footnotetext{
${ }^{1}$ Serviço ofertado pela Brigada Militar do Rio Grande do Sul com o objetivo de fiscalizar e monitorar o cumprimento da Medida Protetiva de Urgência por parte dos agressores/acusados. Dessa forma, a atuação visa a proteger a mulher e prevenir e impedir novos atos violentos.
}

reconhecem instituições/serviços destinados ao enfrentamento do problema vivenciado por elas. Da mesma forma, o fato de as instituições/serviços encaminharem para o CREAS pode revelar que a rede identifica a complexidade que envolve a violência e a demanda por atendimento psicossocial. O CREAS oferta o serviço de Proteção e Atendimento Especializado a Famílias e Indivíduos (PAEFI), que abarca o atendimento psicossocial das mulheres que vivenciaram situações de violência doméstica e/ou familiar. As principais atividades desenvolvidas são: 
acolhida, acompanhamento psicossocial, entrevista, visita domiciliar, intervenções grupais e articulação em rede (Conselho Federal de Psicologia [CFP], 2013). As políticas de intervenção psicossocial são consideradas um aspecto essencial para a proteção às mulheres em situação de violência (Brasil, 2018) e, por isso, a entrada das mulheres no CREAS é mais uma etapa fundamental.

É possível também identificar que dentre os 66 casos que foram encaminhados para o CREAS apenas 38 casos receberam efetivamente algum atendimento. Dessas, 14, representando $36,8 \%$ dos casos, passaram apenas pelo acolhimento inicial, não retornando para os próximos atendimentos. $\mathrm{O}$ acolhimento é um dos maiores objetivos dos atendimentos à mulher em situação de violência (Belarmino, Silva, Santos, \& Dimenstein, 2020) e serve como uma ferramenta importante para evitar que o risco de violência venha a se elevar (Ávila, 2018). Por ser o primeiro contato com o serviço pode ser marcador da futura adesão ou não. A literatura sugere que ainda existem desafios e fragilidades no acolhimento prestado pela rede, por vezes, condicionado à sensibilidade do profissional (Pasinato, 2015), já que faltam protocolos padronizados para o acolhimento e atendimento. Atuações estereotipadas de gênero, posturas moralistas e duais sobre os papéis de vítima-agressor também são identificadas (Belarmino et al., 2020). A forma como o acolhimento é feito, seja em qual for o serviço ofertado na rede, pode influenciar na experiência de enfrentamento e na prevenção da revitimização (Castro \& Silva, 2017). Nesse estudo, não foi objetivo avaliar o tipo de acolhimento e nem seria possível devido à escassez de informação. Dados faltantes não são exclusividade deste estudo (Romagnoli et al., 2013). O não preenchimento deixa lacunas importantes e informações a cargo de quem atendeu a mulher, fato que prejudica o fluxo e a proposição de novas estratégias. Portanto, os dados obtidos não permitem ir além da informação precisa de que 14 casos não retornaram. Para situações desse tipo se recomenda a busca ativa para compreender os motivos da não adesão ou a identificação de novas situações ou risco para a mulher, sendo uma ferramenta de enfrentamento e até mesmo prevenção novos casos (Barbiani, Nora \& Schaefer, 2016).

Neste estudo, os dados mostram apenas o caminho ou a "rota crítica" como vários autores têm denominado (Arboit, Padoin, \& Paula, 2019), por isso não é possível compreender quais fatores foram importantes e quais contribuíram para a chegada da mulher. No entanto, a análise dos dados obtidos nos prontuários permite traçar um perfil do grupo atendido e levantar algumas hipóteses (ver Tabela 1).

Tabela 1

Frequência absoluta e percentual das variáveis individuais de mulheres em situação de violência atendidas no CREAS no ano de 2019

\begin{tabular}{lcc}
\hline \multicolumn{1}{c}{ Características } & N & \% \\
\hline Idade (anos completos) & & \\
$17-26$ & 10 & 26,3 \\
$27-36$ & 9 & 23,7 \\
$37-46$ & 12 & 31,6 \\
$47-56$ & 3 & 7,9 \\
$57-66$ & 2 & 5,3 \\
Não informado & 2 & 5,3 \\
\hline Cor da pele & 21 & \\
Branca & 7 & 55,3 \\
Negra ou parda & 10 & 18,4 \\
Não informado & & 26,3 \\
\hline Escolaridade & 8 & 21,1 \\
Fundamental incompleto & & \\
\hline
\end{tabular}




\begin{tabular}{lcc}
\hline Fundamental completo & 2 & 5,3 \\
Médio completo & 3 & 7,9 \\
Superior completo & 1 & 2,6 \\
Não informado & 24 & 63,2 \\
\hline Trabalho & & \\
Desempregada & 5 & 13,2 \\
Não trabalha & 4 & 10,5 \\
Trabalhando & 10 & 26,4 \\
Não informado & 19 & 50 \\
\hline Recebeu Benefício Social & & \\
Governamental & 18 & 47,4 \\
Sim & 10 & 26,3 \\
Não & 10 & 26,3 \\
Não informado & & \\
\hline Filhos & & \\
Sim & 31 & 81,6 \\
Não & 1 & 2,6 \\
Não informado & 6 & 15,8 \\
\hline
\end{tabular}

Em média, as mulheres que chegaram ao CREAS e receberam atendimento tinham 36 anos, em um intervalo de 17 e 66 anos, faixa etária similar aquela encontrada no Mapa da Violência Contra a Mulher (2018), o qual indica que a maioria das mulheres que sofrem violência doméstica possui entre 18 e 59 anos de idade (Brasil, 2018). Além disso, dentre as notificações, ao Sistema de Vigilância de Violências e Acidentes (VIVA), em 2013 e 2014, de violência doméstica, sexual e/ou outras violências praticadas contra a mulher, as de 15 a 39 anos ocuparam as maiores proporções de ocorrência de violência (Brasil, 2017). Neste estudo, ao analisar a escolaridade é possível verificar que a maior concentração está na categoria "fundamental incompleto". Dado também similar evidências que sugerem que mulheres que já sofreram violência perpetrada por seu parceiro íntimo têm 8 anos ou menos de estudo (Schraiber, Latorre, França Jr, Segri, \& d'Oliveira, 2010; Barros et al., 2016).

Dos $50 \%$ dos registros que continham a informação da profissão das mulheres, 13,2\% estavam desempregadas, $10,5 \%$ não trabalhavam e o restante, em sua maioria, tinham profissões ligadas a tarefas domésticas (faxineira, auxiliar de limpeza, diarista). E quase metade $(47,4 \%)$ destas mulheres recebia algum auxílio financeiro do governo como, por exemplo, Bolsa Família ou Benefício de
Prestação Continuada. Ainda, relacionado a filhos, $81,6 \%$ tinham filhos, ao passo que em $13,2 \%$ dos registros esta informação não constava e em apenas 2,6\% dos casos, não tinham filhos. A dependência econômica do parceiro e a presença de filhos podem ser fatores que contribuem para a perpetuação do relacionamento violento (Carneiro \& Fraga, 2012; Zacan et al., 2013). A desigualdade de gênero pode estar mais presente em famílias em que a posição de provedor econômico está no homem, e a responsabilidade do cuidado da casa e dos filhos está na mulher (Zacan et al., 2013).

Tomados em conjunto esses dados sugerem que as mulheres que se beneficiaram do atendimento do CREAS possuem características de maior vulnerabilidade psicossocial. São mulheres jovens, pouco escolarizadas, com vínculos frágeis de trabalho, com dificuldades financeiras e com filhos. É possível que esse perfil seja mais comumente encontrado em serviços públicos. Romagnoli et al. (2013) encontraram uma maior concentração de registros de boletins de ocorrência, devido à violência doméstica em bairros com vulnerabilidade socioeconômica. Entretanto, reforçam que a violência não está associada a pobreza, uma vez que esta, não discrimina camada social, apenas pode ser mais difundida nesse estrato social, especialmente, considerando que as camadas médias e altas 
possuem outras formas de lidar com o fenômeno como, por exemplo, mantendo a violência como um segredo familiar (Mascarini \& Miranda, 2018; Romagnoli et al., 2013). Soma-se a isso a possibilidade de que pessoas com recursos financeiros busquem ajuda em serviços não públicos.

Curia et al. (2020) ainda destacam que, "é fundamental reconhecer a invisibilidade de marcadores de raça e etnia na compreensão do fenômeno da violência contra a mulher" (Curia et al., 2020, p. 13). Neste estudo mais da metade dos registros de mulheres em situação de violência eram de pessoas brancas $(55,3 \%) \mathrm{e}$ apenas $18,4 \%$ das mulheres não são brancas. Estes dados não corroboram com as informações do Atlas da Violência, o qual menciona uma taxa de violência letal entre mulheres negras de $66 \%$ de todas as mulheres assassinadas no país em 2017 (Brasil, 2019). Além disso, é registrado um aumento nos assassinatos de mulheres negras (54\%) entre 2003 e 2013, enquanto o de brancas diminuiu (9,8\%) (Waiselfisz, 2015). Entretanto, esses dados podem referir características específicas e locais da população investigada, já que o Rio Grande do Sul é um Estado majoritariamente branco (IBGE, 2016). Por outro lado, não se pode descartar a dificuldade de garantia da universalidade das políticas públicas para mulheres em situação de violência, considerando que existe uma literatura que sugere que mulheres jovens e negras sejam mais vulneráveis à violência, tanto dentro como fora de casa (Engel, 2020).

De acordo com o Mapa da Violência Contra a Mulher (2018), a cada 17 minutos uma mulher sofre violência física no Brasil, a cada 30 minutos violência psicológica ou moral e a cada 24 horas, 8 casos de violência sexual são descobertos no país. Em 76,2\% dos documentos, as mulheres haviam sofrido violência psicológica associada ou não a outro tipo de agressão. Já a violência física esteve presente em $65,8 \%$ dos casos, seguida da sexual $(10,5 \%)$, patrimonial $(7,8 \%)$ e moral $(5,2 \%)$. No total de pastas analisadas ( $\mathrm{n}=38), 5,3 \%$ não tinha a informação referente ao tipo de violência sofrida pelas mulheres. Interessante apontar que a violência psicológica foi bastante notificada, sugerindo um possível avanço em seu reconhecimento (Curia et al., 2020). Esta apresenta uma possibilidade de evolução para outras manifestações de violência potencialmente letal (Ávila, 2018) e é apontada como a mais dolorosa (Sagot, 2007, citado por Zacan et al., 2013). Em geral, as violências com maior prevalência são: psicológica, física e sexual (IBGE, 2014; Brasil, 2015; Barros \& Schraiber, 2017), e casos de violência patrimonial e a moral tem menor visibilidade na população (IBGE, 2014; Brasil, 2015). As informações coletadas com base nos atendimentos do CREAS estão de acordo com os dados já apontados na literatura.

Como esperado $92,1 \%$ dos casos analisados envolviam violência perpetrada por parceiro íntimo, apenas em 7,9\% foi cometido por outra pessoa. A violência cometida por parceiro íntimo é o tipo com maior prevalência neste contexto (Silva \& Oliveira, 2015). A análise do tempo médio de relacionamento com o agressor, identificado na análise documental, foi de aproximadamente 12 anos e meio. Os dados coletados não permitem afirmar qualquer tipo de correlação entre tempo de relacionamento e tempo de violência. Estudos futuros podem explorar melhor essas variáveis. Pesquisadores têm sugerido vários fatores individuais e contextuais que contribuem para a vulnerabilidade (Adeodato et al., 2005; Barros et al., 2016; Mascarini \& Miranda, 2018; Vieira et al., 2011). Fatores do comportamento do agressor também podem ter relação com esse tema. Mais da metade dos registros revelavam que o agressor fazia uso álcool e/ou outras drogas (52,6\%). Em um estudo de Moraes, Cavalcante, Pantoja e Costa (2018) foi identificado que a maioria dos agressores também fazia uso de bebida alcoólica (51,3\%) e de drogas ilícitas (12\%). A presença de álcool e/ou outras drogas pode ser um fator de risco para a ocorrência de situações violentas (Curia et al., 2020; Zacan et al., 2013) e mais graves (Romagnoli et al., 2013).

Em 68,4\% dos casos, as mulheres solicitaram medida protetiva. Em $28,9 \%$ não constava esta informação e em $2,6 \%$ não foi 
solicitada a medida. As mulheres tendem a buscar ajuda profissional da rede de suporte social, principalmente, quando há risco de morte (Labronici, 2012). Semanalmente, 33 mulheres são assassinadas pelo parceiro atual ou antigo, sendo que em $75 \%$ dos casos de ataque, a situação se repete por até 5 anos (Brasil, 2018). As medidas protetivas de urgência têm objetivo de acelerar os procedimentos da Lei Maria da Penha para manter a integridade da mulher durante o andamento da persecução penal (Carneiro \& Fraga, 2012). Esse dado pode sugerir que as mulheres que seguem nos caminhos do atendimento ou na rota são aquelas que vivenciam casos de maior gravidade e que já foram publicizados. A sua adesão e manutenção aos serviços pode ser um indicador de segurança.

Vale mencionar que o atendimento prestado no CREAS não esgota as possibilidades de articulação com a rede local. Para que o atendimento integral aconteça as demandas trazidas pela mulher precisam ser contempladas no trabalho intersetorial, sem hierarquia e apoiado por estratégias efetivas (d'Oliveira et al., 2009; Sani \& Morais, 2015; WHO, 2013). A Figura 1 evidencia as articulações promovidas pelo CREAS, os encaminhamentos realizados foram feitos durante e depois do atendimento realizado no serviço. Nos documentos referentes às 38 mulheres atendidas, em $44,7 \%$ não constava a informação de nenhum encaminhamento realizado. Fato que pode estar relacionado ao não seguimento das mulheres aos atendimentos, à falta de padronização nos registros documentais ou à falta de articulação com a rede. Rosa e Nascimento (2018) destacam a importância do trabalho em rede e da articulação do CREAS com os serviços ofertados no município. É fundamental que os profissionais da rede compreendam que o seu papel precisa incorporar essas conexões que vão muito além do encaminhamento.

Dos encaminhamentos realizados, é possível identificar que foram acionados serviços de saúde, assistência jurídica e assistência social, sendo que em $15,8 \%$ dos registros mais de um setor foi recomendado. Os encaminhamentos se mostram essenciais para o rompimento do ciclo da violência e para a realização e sustentação da notificação, sendo importantes ferramentas para a promoção de autonomia econômica e emocional destas mulheres (Ávila, 2018). É sabido que os serviços são acionados a partir das demandas trazidas pela mulher, no entanto, quando são realizados poucos encaminhamentos $\mathrm{e}$ acompanhamentos na rede podem haver prejuízos no atendimento integral (Curia et al., 2020).

A ineficiência da rede intersetorial de apoio pode contribuir para a perpetuação da violência, fazendo com que as mulheres não queiram notificar os agressores e procurar ajuda (Souza et al., 2018), ainda tenham vontade de abandonar os atendimentos. Com uma infraestrutura precária e falta de recursos humanos especializados a articulação de serviços da rede de enfrentamento passa a ser um grande desafio (Curia et al., 2020). Somado a esse contexto, estão as frágeis e precárias normas que orientam a atuação dos profissionais e a carência de formação, o que contribui para práticas pouco respaldadas pelas políticas públicas e compromete o desenvolvimento adequado das ações no âmbito local (Souza \& Rezende, 2018). Dessa forma, é pertinente que seja realizada uma problematização de dados de pesquisa e uma reflexão crítica acerca de experiências de atenção às mulheres (Meneghel \& Vial, 2008).

Devido a natureza multicausal da violência doméstica, a intervenção torna-se complexa, com caminhos não lineares e necessidades diversas. Para abarcar esta complexidade e multidimensionalidade, é necessário que a rede de enfrentamento da violência contra a mulher (saúde, segurança pública, assistência social, entre outras) esteja articulada e o atendimento às mulheres seja imediato (Brasil, 2011c; Brasil, 2018). A Psicologia assume um papel importante na rede de serviços de atendimento e na produção científica acerca da violência contra a mulher, sendo assim ela também pode contribuir com a formulação de políticas públicas para o 
enfrentamento do fenômeno (Curia et al., 2020). A elaboração destas estratégias se torna mais eficaz se construída a partir de dados sobre a população que por ela será atendida (Moraes et al., 2018). Ávila (2018) demonstra a construção do "Projeto de proteção integral à mulher em situação de violência doméstica", como um exemplo de ação de articulação em rede. $\mathrm{O}$ autor detalha a proposta e apresenta as etapas possíveis. A primeira delas envolve a identificação dos fatores de risco, realizada através de um formulário preenchido pela mulher em situação de violência. A partir das informações registradas são desenvolvidas ações de proteção individualizadas e é planejado o acompanhamento psicossocial. Para a articulação da rede, são propostas estratégias diversas como, por exemplo, o mapeamento dos serviços disponíveis para atendimento às mulheres, a criação de uma comissão local para articulação da rede e a proposição de reuniões mensais com representantes. Também são previstos acompanhamentos psicossociais com os autores das agressões com o objetivo prevenir a ocorrência de outros atos de violência doméstica contra a mulher. Para o monitoramento das medidas protetivas de urgência são propostas atividades de comunicação entre os integrantes da rede com o Sistema de Justiça (Ávila, 2018).

Outro projeto de boas práticas é sugerido por Oliveira (2020), o projeto intitulado "Rede Mulher: desenvolvimento de política pública de enfrentamento à violência doméstica e familiar contra a mulher em Turmalina/MG", tem como objetivo "promover a integração entre os órgãos de defesa social". Como resultados, desde a criação deste projeto, $\mathrm{o}$ atendimento da mulher em situação de violência e seus familiares passou a ocorrer de forma mais solidária, humanizada e articulada com as políticas públicas. Além disso, a partir da qualificação do atendimento, foi identificada maior confiança das mulheres no serviço prestado. Além disso, os dados estatísticos da Polícia Militar evidenciam que os casos de violência doméstica e familiar contra a mulher diminuíram (em 2017 e 2018) com a criação da rede de enfrentamento (Oliveira, 2020).

\section{Caminhos e perdas na rede de proteção}

O desenho do fluxo dos casos que chegaram ao CREAS ajuda a perceber quantos casos ficam sem atendimento (ver Figura 1). A análise das portas de entrada desses 28 casos que foram encaminhados, mas não receberam atendimento no CREAS revela que $46,4 \%$ haviam sido encaminhadas pelo sistema de justiça, 35,7\% pela casa de acolhida, 7,2\% pela assistência social, $7 \%$ pelo Conselho Tutelar e $3,6 \%$ pelo sistema de justiça e pela segurança pública. Não foi possível conhecer os motivos da não adesão ou da não ida ao local indicado, mas pensando que o destino do encaminhamento era o CREAS algumas hipóteses podem ser levantadas. A literatura já aponta que a falta de adesão é um grande obstáculo enfrentado nos atendimentos psicossociais realizados no CREAS (Souza \& Rezende, 2018). Maffei et al. (2020) ao ouvir mulheres que buscaram a Delegacia Especializada identificaram que a maior parte delas compreende a violência como um problema que precisa ser resolvido pela segurança pública e reluta na busca por ajuda na saúde e na assistência por acreditar que quem precisa do acompanhamento é o agressor, já que ele é quem age de forma inadequada na avaliação da mulher. Talvez a não compreensão da violência como um problema de saúde pública que envolve todos aqueles que estão diretamente e indiretamente vinculados ao fato prejudique a manutenção da mulher na rota ou no caminho de busca por ajuda. Outros fatores como os aspectos afetivos e financeiros (Adeodato et al., 2005; Barros et al., 2016; Vieira et al., 2013), os estereótipos de gênero (Romagnoli et al., 2013) e serviços precários (Curia et al., 2020; Souza et al. 2018) também são elementos essenciais na compreensão das falhas nos fluxos de atendimento e precisam ser incluídos na discussão sobre as rotas e as perdas.

Meneghel e Vial (2008) destacam que o percurso das mulheres após a decisão de 
romper com a violência é longo, com avanços e retrocessos, desprovido de apoio e em muitas vezes revitimizador. Mesmo com a existência de uma rede de proteção, com serviços especializados, a atuação da mulher em busca de recursos para sair do circuito da violência se apresenta de forma isolada e não evita sua exposição a novas violências (Bruhn \& Lara, 2016). A existência da rede não garante proteção integral por si só. Os 28 casos encaminhados para o CREAS e que não foram atendidos pelo dispositivo foram arquivados. Lima et al. (2020) afirmam que aguardar o deslocamento de mulheres que sofrem violência de gênero até o serviço aumenta os riscos de lesões e danos causados pela agressão. A busca ativa pode ser uma alternativa para tais situações, já que é caracterizada como uma valiosa ferramenta no combate à violência, a partir dela, é possibilitada a realização de ações mais efetivas e a prevenção de novos casos (Barbiani et al., 2016). O Conselho Federal de Psicologia (2013) menciona a prática como uma modalidade inovadora para o trabalho da Psicologia no CREAS.

É preciso que exista um investimento maior na busca das mulheres em situação de violência. Segundo Arboit et al., (2019), quebrar o silêncio da situação de violência e tornar ela pública, demonstra a abertura da mulher para busca de apoio nas redes e nos serviços. Porém, as ações e os encaminhamentos realizados podem não permitir acolhimento $\mathrm{e}$ atendimento às mulheres e a realidade do trabalho pode comprometer o processo de notificação e o desenvolvimento de adequado do processo de atendimento (Souza \& Rezende, 2018). A busca ativa enfrenta a invisibilidade proporcionada pela violência. A mulher precisa ser impulsionada a sair do anonimato e a conhecer seus direitos (Carneiro \& Fraga, 2012).

\section{Considerações Finais}

O caminho percorrido pela mulher nos mais diversos serviços da rede de proteção ainda é frágil, cheio de intercorrências e rupturas. Na maior parte das vezes, a mulher em situação de violência inicia a busca por ajuda sozinha, sem apoio da comunidade e das suas redes de apoio e proteção (familiar ou extrafamiliar). Esse isolamento pode acontecer por medo, vergonha ou culpa e pode acabar sustentando um sistema fechado e com fronteiras enrijecidas que contribui para a sustentação da condição de vulnerabilidade. Por esse motivo quando uma mulher chega a um serviço, qualquer que seja, é de extrema importância que ela receba todo o investimento para ter na rede o apoio e a referência que precisa. $\mathrm{O}$ estudo evidenciou que as mulheres em situação de violência percorrem serviços de segurança, assistência e saúde e cada rota é singular. Foram observados diferentes fluxos de atendimentos e os encaminhamentos. O CREAS foi referência e contrarreferência para diferentes setores o que pode favorecer o atendimento integral, no entanto, ainda é preciso atentar para fluxos que não "empurrem" a mulher para fora da rede.

O fluxo de atendimento e proteção precisa acontecer por meio de ações intersetoriais, articuladas e não hierarquizadas. Não importa a porta de entrada, todas precisam estar abertas, em comunicação e preparadas para acolher as demandas trazidas pela mulher e pelo sistema familiar que a acompanha, especialmente quando existem filhos presentes. Todos precisam estar e se sentir protegidos. É possível identificar que quando a mulher está dentro da rede faz uso dos mais diversos serviços disponíveis a ela. A sua adesão e manutenção aos serviços parece ser um indicador de segurança, isto é, dentro da rede se percebe protegida contra novas ocorrências e encontra espaço para ser protagonista da sua história. Embora o estudo se limite a descrever dados documentais de um serviço da política de assistência social é possível identificar sua relação com os mais diversos setores que precisam estar conectados para que a rede de proteção funcione. Contudo, como na maior parte dos estudos documentais, os dados estão restritos a um recorte no tempo $\mathrm{e}$ as informações que ali constavam. A não padronização dos registros e a falta de preenchimento foi uma importante limitação 
que parece ainda ser um grande problema nessa estratégia metodológica. Mesmo diante dessas restrições, os resultados apresentados podem auxiliar na compreensão do funcionamento e articulação da rede de proteção a mulheres em situação de violência. Esses, podem fomentar pesquisas futuras e propostas que proporcionem melhor comunicação entre os serviços, padronização de atendimento e acolhimento destas mulheres bem como o acesso delas ao serviço.

\section{Referências}

Adeodato, V. G., Carvalho, R. R., Siqueira, V. R., \& Souza, F. G. M. (2005). Qualidade de vida e depressão em mulheres vítimas de seus parceiros. Revista de Saúde Pública, 39(1), 108-113. doi: 10.1590/S003489102005000100014

Arboit, J., Padoin, S. M. M., \& Paula, C. C. (2019). Rota crítica de mulheres em situação de violência: revisão integrativa da literatura. Revista Brasileira de Enfermagem, 72 (Suppl. 3), 321-332. doi: 10.1590/0034-7167-2018-0265

Ávila, T. A. P. (2018). Articulação do trabalho em rede para a proteção à mulher em situação de violência doméstica e familiar. In: Brasil. Conselho Nacional do Ministério Público. Violência contra a mulher: um olhar do Ministério Público brasileiro (pp. 141-163). Brasília: CNMP

Barbiani, R., Nora, C. R. D., \& Schaefer, R. (2016). Nursing practices in the primary health care context: a scoping review. Revista Latino-Americana de Enfermagem, 24, e2721. doi: 10.1590/15188345.0880.2721

Barbosa, T. P., Corrêa, M. A., Zimmer, M., \& Paludo, S. S. (2019). Domínios

Esquemáticos Apresentados por Mulheres em Situação de Violência Conjugal. Revista de Psicologia da IMED, 11(2), 51-68. doi: 10.18256/2175-5027.2019.v11i2.2982

Barros, C. R. S., \& Schraiber, L. B. (2017). Violência por parceiro íntimo no relato de mulheres e de homens usuários de unidades básicas. Revista Saúde Pública, 51(7). doi: 10.1590/s1518-8787.2017051006385

Barros, E. N., Silva, M. A., Neto, G. H. F., Lucena, S. G., Ponzo, L., \& Pimentel, A. P. (2016). Prevalência e fatores associados à violência por parceiro íntimo em mulheres de uma comunidade em
Recife/Pernambuco, Brasil. Ciência e Saúde Coletiva, 21(2), 591 598. doi: 10.1590/1413-81232015212.10672015

Belarmino, V. H., Silva, J. C. A., Santos, L. L. A., \& Dimenstein, M. (2020). Reflexões sobre Práticas e Cotidiano Institucional na Rede de Proteção à Mulher. Psicologia: Ciência e Profissão, 40, e200160. doi: 10.1590/1982-3703003200160

Brasil (2011a). Política Nacional de Enfrentamento à Violência contra as Mulheres. Secretaria Nacional de Enfrentamento à Violência contra as Mulheres. Secretaria de Políticas para as Mulheres. Ministério da Justiça. Brasília, DF: Coleção Enfrentamento à Violência contra as Mulheres. Recuperado de https://www12.senado.leg.br/institucional/o mv/entenda-a-violencia/pdfs/politicanacional-de-enfrentamento-a-violenciacontra-as-mulheres

Brasil (2011b). Rede de Enfrentamento à Violência contra as Mulheres. Brasília: Ideal Gráfica e Editora. Presidência da República. Secretaria de Políticas para as Mulheres. Secretaria Nacional de Enfrentamento à Violência contra as Mulheres.

Brasil (2011c). Política Nacional de Enfrentamento à Violência contra as Mulheres. Secretaria de Políticas para as Mulheres Presidência da República. Brasília: Ideal Gráfica e Editora. Recuperado de https://www12.senado.leg.br/institucional/o mv/entenda-a-violencia/pdfs/politicanacional-de-enfrentamento-a-violenciacontra-as-mulheres

Brasil (2015). Violência doméstica e familiar contra a mulher. Secretaria da Transparência. Senado Federal. Serviço de 
Pesquisa DataSenado. Recuperado de http://www12.senado.leg.br/senado/procura doria/publicacao/pesquisaviolenciadomestica-e-familiar-contra-asmulheres

Brasil (2017). Viva: Vigilância de Violências e Acidentes: 2013 e 2014. Brasília:

Ministério da Saúde. Secretaria de Vigilância em Saúde. Departamento de Vigilância de Doenças e Agravos não Transmissíveis e Promoção da Saúde. Recuperado de http://bvsms.saude.gov.br/bvs/publicacoes/ viva_vigilancia_violencia_acidentes_2013 2014.pdf

Brasil (2018). Mapa da Violência contra a Mulher. Comissão de Defesa dos Direitos da Mulher. Câmara de Deputados. Brasília, DF. Recuperado de https://www2.camara.leg.br/atividadelegislativa/comissoes/comissoespermanentes/comissao-de-defesa-dosdireitos-da-mulher-cmulher/arquivos-deaudio-evideo/MapadaViolenciaatualizado200219.p $\underline{\text { df }}$

Brasil (2019). Atlas da Violência. Instituto de Pesquisa Econômica Aplicada - IPEA. Fórum Brasileiro de Segurança Pública. Brasília, DF. Recuperado de https://www.ipea.gov.br/atlasviolencia/dow nload/19/atlas-da-violencia-2019

Bruhn, M. M., \& Lara, L. (2016). Rota crítica: a trajetória de uma mulher para romper o ciclo da violência doméstica. Revista Polis e Psique, 6(2), 70-86. Recuperado de http://pepsic.bvsalud.org/scielo.php?script= sci_arttext\&pid=S2238152X2016000200005\&lng=pt\&tlng=pt.

Bruschi, A., Paula, C. S., \& Bordin, I. A. S. (2006). Prevalência e procura de ajuda na violência conjugal física ao longo da vida. Revista de Saúde Pública, 40(2), 256-64. doi: 10.1590/S0034-89102006000200011

Carneiro, A. A., \& Fraga, C. K. (2012). A Lei Maria da Penha e a proteção legal à mulher vítima em São Borja no Rio Grande do Sul: da violência denunciada à violência silenciada. Serviço Social \& Sociedade,
110, 369-397. doi: 10.1590/S010166282012000200008

Castro, B. D. V., \& Silva, A. S. (2017). Atuação da autoridade policial e do poder judiciário no combate à violência doméstica contra a mulher na cidade de São Luís/MA. Revista Opinião Jurídica, 15(20), 59-83. doi: 10.12662/2447-6641oj.v15i20.p5983.2017

Conselho Federal de Psicologia [CFP]. (2013). Referências técnicas para Prática de Psicólogas(os) no Centro de Referência Especializado da Assistência Social CREAS. Brasília, DF: CFP. Recuperado de https://site.cfp.org.br/publicacao/referencias -tecnicas-sobre-a-pratica-de-psicologas-osno-centro-de-referencia-especializado-daassistencia-social-creas/

Cunha, T. R. A. (2008). Violência conjugal: Os ricos também batem. UEPG Humanas, 16(1), 167-176. doi: 10.5212/publ.humanas.v16i1.628

Curia, B. G., Dias, V., Zamora, J. C., Ruoso, A., Ligório, I. S., \& Habigzang, L. (2020). Produções científicas brasileiras em Psicologia sobre violência contra mulher por parceiro íntimo. Psicologia: Ciência e Profissão, 40, 1-19. doi: 10.1590/19823703003189184

d'Oliveira, A. F. P. L., Schraiber, L. B., Hanada, H., \& Durand, J. (2009). Atenção integral à saúde de mulheres em situação de violência de gênero: uma alternativa para a atenção primária em saúde. Ciência \& Saúde Coletiva, 14(4), 1037-1050. doi: 10.1590/S1413-81232009000400011

Engel, C. L. (2020). A Violência Contra a Mulher. In N. Fountana, M. Rezende, \& A. C. Querino (Org.), Beijing +20: avanços e desafios no Brasil contemporâneo (pp. 159215). Brasília: Instituto de Pesquisa Econômica Aplicada - Ipea.

Farinha, M. G., \& Souza, T. M. C. (2016). Plantão Psicológico na Delegacia da Mulher: experiência de atendimento sócioclínico. Revista da SPAGESP, 17(1), 65-79. Recuperado de http://pepsic.bvsalud.org/scielo.php?script= sci_arttext\&pid=S1677$29702016000100007 \& \operatorname{lng}=$ pt\&tlng=pt. 
Gil, A. C. (2002). Como elaborar projetos de pesquisa (4 ed.). São Paulo: Atlas.

Gomes, R., Minayo, M. C. S., \& Silva, C. F. R. (2005). Violência contra a mulher: Uma questão transnacional e transcultural das relações de gênero. In Brasil, Ministério da Saúde. Secretaria de Vigilância em Saúde. Impacto da violência na saúde dos brasileiros (pp.117-140). Brasília, DF.

Instituto Brasileiro de Geografia e Estatística [IBGE]. (2010). Censo brasileiro de 2010. Rio de Janeiro: IBGE.

Instituto Brasileiro de Geografia e Estatística [IBGE]. (2014). Direitos Humanos. Recuperado de

http://www.ibge.gov.br/home/estatistica/popul acao/condicaodevida/indicadoresminimos/s inteseindicsociais2012/default_tab_pdf.sht $\underline{m}$

Instituto Brasileiro de Geografia e Estatística [IBGE]. (2016). Pesquisa Nacional por a Amostra de Domicílio (PNAD). Rio de Janeiro: IBGE.

Krenkel, S., \& Moré, C. L. O. O. (2017). Violência contra a Mulher, Casas-Abrigo e Redes Sociais: Revisão Sistemática da Literatura. Psicologia: Ciência e Profissão, 37(3), 770-783. doi: 10.1590/19823703000192016

Labronici, L. M. (2012). Processo de resiliência nas mulheres vítimas de violência doméstica: um olhar fenomenológico. Texto \& Contexto Enfermagem, 21(3), 625-632. doi: 10.1590/S0104-07072012000300018

Lei $n$. 11.340, de 7 de agosto de 2006. Cria mecanismos para coibir a violência doméstica e familiar contra a mulher, nos termos do $\S 8^{\circ}$ do art. 226 da Constituição Federal, da Convenção sobre a Eliminação de Todas as Formas de Discriminação contra as Mulheres e da Convenção Interamericana para Prevenir, Punir e Erradicar a Violência contra a Mulher; dispõe sobre a criação dos Juizados de Violência Doméstica e Familiar contra a Mulher; altera o Código de Processo Penal, o Código Penal e a Lei de Execução Penal; e dá outras providências. Recuperado de http://www.planalto.gov.br/ccivil_03/ato2 004-2006/2006/lei/111340.htm

Lei n. 13.104, de 9 de março de 2015. Altera o art. 121 do Decreto-Lei ${ }^{\circ} 2.848$, de 7 de dezembro de 1940 - Código Penal, para prever o feminicídio como circunstância qualificadora do crime de homicídio, e o art. $1^{\circ}$ da Lei $\mathrm{n}^{\circ} 8.072$, de 25 de julho de 1990, para incluir o feminicídio no rol dos crimes hediondos. Recuperado de http://www.planalto.gov.br/ccivil_03/_ato2 015-2018/2015/lei/113104.htm

Lima, J. C. V., Santos, R. C., Silva, J. C., Silva R. S. C., Souto C. M. R. M., Souto R. Q., ... Araújo, G. K. N. (2020). Rastreio e encaminhamento de casos de violência contra a mulher por enfermeiras na estratégia saúde da família. Cogitare Enfermagem, 25, e65579. doi:

10.5380/ce.v25i0.65579

Maffei, B., Marcos, C. \& Paludo, S. (2020). Motivações e expectativas de mulheres em situação de violência no momento da denúncia em uma delegacia especializada em atendimento à mulher, Psicologia em Revista, 26(1), 165-186. doi: 10.5752/P.1678-9563.2020v26n1p161-180

Mascarini, S. M., \& Miranda, K. P. (2018). Atuação da Psicologia no Âmbito da Violência Conjugal em uma Delegacia de Atendimento à Mulher. Pensando Famílias, 22(1), 163-178. Recuperado de http://pepsic.bvsalud.org/scielo.php?script= sci_arttext\&pid=S1679494X2018000100013\&lng $=p t \& t \operatorname{lng}=p t$

Mendonça, M. F. S., \& Ludermir, A. B. (2017). Violência por parceiro íntimo e incidência de transtorno mental comum. Revista de Saúde Pública, 51, 32. doi: 10.1590/s1518-8787.2017051006912

Meneghel, S., \& Vial, S. (2008). Rotas críticas: mulheres enfrentando as violências. Athenea Digital, 14, 199-213.

Recuperado de http://psicologiasocial.uab.es/athenea/index .php/atheneaDigital/article/view/533

Moraes, M. S. B., Cavalcante, L. I. C., Pantoja, Z. C., \& Costa, L. P. (2018) Violência por Parceiro Íntimo: Características dos Envolvidos e da 
Agressão. PSI UNISC, 2(2), 78-96. doi: 10.17058/psiunisc.v2i2.11901

Narvaz, M. G., \& Koller, S. H. (2006). Mulheres vítimas de violência doméstica: compreendendo subjetividades assujeitadas. Psico, 37(1), 7-13. Recuperado de https://revistaseletronicas.pucrs.br/ojs/index .php/revistapsico/article/view/1405

Oliveira, S. M. (2020). Projeto "rede mulher": desenvolvimento de política pública de enfrentamento à violência doméstica e familiar contra a mulher em Turmalina/MG. Revista da ENAMP, 14-41. Recuperado de http://revista.enamp.org.br/index.php/revist aenamp/article/view/15

Pasinato, W. (2015). Acesso à justiça e violência doméstica e familiar contra as mulheres: as percepções dos operadores jurídicos e os limites para a aplicação da Lei Maria da Penha. Revista Direito GV, 11(2), 407-428. doi: 10.1590/18082432201518

Resolução $n^{\circ}$ 510, de 07 de abril de 2016. O Plenário do Conselho Nacional de Saúde em sua QuinquagésimaNona Reunião Extraordinária, realizada nos dias 06 e 07de abril de 2016, no uso de suas competências regimentais e atribuiçõesconferidas pela Lei n. 8.080, de 19 de setembro de 1990 , pela Lei n. 8.142, de 28 de dezembro de 1990, pelo Decreto n 05.839, de 11 de julho de 2006. Recuperado de https://www.in.gov.br/materia//asset_publisher/Kujrw0TZC2Mb/content/i $\mathrm{d} / 22917581$

Ribeiro, C. G., \& Coutinho, M. D. P. L. (2011). Representações sociais de mulheres vítimas de violência doméstica na cidade de João Pessoa-PB. Revista Psicologia e Saúde, 3(1), 52-59. Recuperado de https://pssaucdb.emnuvens.com.br/pssa/arti cle/view/81

Romagnoli, R. C., Abreu, L. L. G., \& Silveira, M. F. (2013). A violência contra a mulher em Montes Claros: análise estatística. Gerais: Revista Interinstitucional de Psicologia, 6(2), 282-297. Recuperado de http://pepsic.bvsalud.org/scielo.php?script=
sci_arttext\&pid=S1983$\underline{82202013000200010 \& \ln g=p t \& t \operatorname{lng}=p t}$

Rosa, N. F., \& Nascimento, C. R. R. (2018). O CREAS PAEFI na perspectiva de mulheres vítimas de violência e profissionais: uma análise a partir da teoria bioecológica do desenvolvimento humano. Psicologia em Revista, 24(3), 661-685. doi: 10.5752/P.1678-9563.2018v24n3p661-685

Sani, A., \& Morais, C. (2015). A polícia no apoio às vítimas de violência doméstica: estudo exploratório com polícias e vítimas. Direito e Democracia, 16(1), 5-18.

Recuperado de http://www.periodicos.ulbra.br/index.php/d ireito/article/view/2282

Schraiber, L. B., Latorre, M. R. D. O, França Jr, I., Segri, N. J., \& d'Oliveira, A. F. P. L. (2010). Validade do instrumento WHO VAW STUDY para estimar violência de gênero contra a mulher. Revista de Saúde Pública, 44(4), 658-666. doi: 10.1590/S0034-89102010000400009

Silva, L. E. L., \& Oliveira M. L. C. (2015). Violência contra a mulher: revisão sistemática da produção científica nacional no período de 2009 a 2013. Ciência e Saúde Coletiva, 20(11), 3523-3532. doi: 10.1590/1413-812320152011.11302014

Silveira, R. S., Nardi, H. C. \& Spindler, G. (2014). Articulações entre gênero e raça/cor em situações de violência de gênero. Psicologia \& Sociedade, 26(2), 323-334. doi: 10.1590/S0102-71822014000500003

Souza, L., \& Cortez, M. B. (2014). A delegacia da mulher perante as normas e leis para o enfrentamento da violência contra a mulher: um estudo de caso. Revista de Administração Pública, 48(3), 621-639. doi: 10.1590/0034-76121141

Souza, T. M. C., \& Rezende, F. F. (2018). Violência contra mulher: concepções e práticas de profissionais de serviços públicos. Estudos Interdisciplinares em Psicologia, 9(2), 21-38. Recuperado de http://pepsic.bvsalud.org/scielo.php?script= sci_arttext\&pid=S223664072018000200003\&lng $=p t \& t \operatorname{lng}=p t$

Souza, T. M. C., Santana, F. R. M., \& Martins, T. F. (2018). Violência contra a mulher, 
polícia civil e políticas públicas. Pesquisas

e Práticas Psicossociais, 13(4), 1-13.

Recuperado de

http://pepsic.bvsalud.org/scielo.php?script= sci_arttext\&pid=S1809$\underline{89082018000400003 \& \operatorname{lng}=\mathrm{pt} \& \mathrm{t} \operatorname{lng}=\mathrm{pt}}$

Tavares, G. P., Rodrigues, M. B., Barroso, M. F., Vieira, N. M. S., \& Sousa, V. R. (2017). Atendimento Humanizado às Mulheres em Situação de Violência: a percepção das mulheres atendidas na DEAM/Parintins, Amazonas. Gênero na Amazônia, 7(12), 135-145. Recuperado de http://www.generonaamazonia.com/edicao7.php

United Nations [ONU]. (1993). Declaration on the elimination of violence against women. General Assembly Resolution $n^{\circ}$. A/RES/48/104, Geneve: United Nations.

Vieira, E. M., Perdona, G. S. V., \& Santos, M. A. (2011). Fatores associados à violência física por parceiro íntimo em usuárias de serviços de saúde. Revista Saúde Pública, 45(4), 730-737. doi: 10.1590/S0034$\underline{89102011005000034}$
Waiselfisz, J. J. (2015). Mapa da Violência 2015: Homicídio de Mulheres no Brasil. Brasília, DF

World Health Organization [WHO]. (2013). Global and regional estimates of violence against women: prevalence and health effects of intimate partner violence and non partner sexual violence. Recuperado de https://www.who.int/publications/i/item/97 89241564625

World Health Organization [WHO]. (2014). Violence against women. Intimate partner and sexual violence against women.

Recuperado de http://www.who.int/mediacentre/factsheets/ fs239/en/

Zacan, N., Wassermann, V., \& Lima, G. Q. (2013). A Violência Doméstica a Partir do Discurso de Mulheres Agredidas. Pensando Famílias, 17(1), 63-76. Recuperado de http://pepsic.bvsalud.org/scielo.php?script= sci_arttext\&pid=S1679$\underline{494 X 2013000100007 \& \operatorname{lng}=p t \& t \operatorname{lng}=p t}$

\section{Dados sobre as autoras:}

- Diênifer Kaus: Psicóloga. Graduada pela Universidade Federal do Rio Grande.

- Thamires Pereira Barbosa: Psicóloga. Mestre em Psicologia pela Universidade Federal de Santa Maria. Doutoranda em Psicologia pela Universidade Federal de Santa Maria.

- Simone dos Santos Paludo: Professora Doutora em Psicologia da Graduação e do Programa de Pós-Graduação em Psicologia - Curso de Mestrado da Universidade Federal do Rio Grande.

\footnotetext{
Declaração de Direito Autoral

A submissão de originais para este periódico implica na transferência, pelos autores, dos direitos de publicação impressa e digital. Os direitos autorais para os artigos publicados são do autor, com direitos do periódico sobre a primeira publicação. Os autores somente poderão utilizar os mesmos resultados em outras publicações indicando claramente este periódico como o meio da publicação original. Em virtude de sermos um periódico de acesso aberto, permite-se o uso gratuito dos artigos em aplicações educacionais e científicas desde que citada a fonte conforme a licença CC-BY da Creative Commons.
} 